\title{
O papel do Instituto de Desenvolvimento Agropecuário e Florestal Sustentável do Estado do Amazonas (Idam) nos serviços de Assistência Técnica e Extensáo Rural (Ater) públicos no estado do Amazonas
}

The role of the Institute for Sustainable Development of Agriculture and Forestry of the State of Amazonas (Idam) in public services of Technical Assistance and Rural Extension 'Ater) in Amazonas state

\section{RESUMO}

O artigo traz uma reflexão sobre os principais serviços desenvolvidos pelo Instituto de Desenvolvimento Agropecuário e Florestal Sustentável do Estado do Amazonas (Idam), com objetivo de analisar a importância da atuação desse órgão para Assistência Técnica e Extensão Rural (Ater) no estado do Amazonas, identificando como é realizada a prestação desses serviços sob a perspectiva da Política Nacional de Assistência Técnica e Extensão Rural (Pnater). Foi possível perceber, por meio do levantamento bibliográfico, que, muito embora, haja falta de incentivo financeiro e muitas limitaçóes da entidade, o que desencadeia grandes problemas, o Idam possui papel preponderante para o desenvolvimento da agricultura familiar no estado, pois tem mediado principalmente o acesso às políticas públicas para os agricultores familiares. Com a implementaçấo da Pnater, houve mudanças na forma de condução dos serviços de Ater no país e, no Amazonas, não foi diferente. Apesar do viés da Ater no estado ainda ser predominantemente difusionista, percebe-se um esforço da entidade de incorporar os eixos que o novo Ater propóe. Desse modo, é possível inferir que os extensionistas da entidade têm atuado dentro das limitaçóes como agentes facilitadores do processo de desenvolvimento rural, ajudando a melhorar a vida dos agricultores do estado por meio dos serviços desenvolvidos.

Palavras-chave: Agricultura familiar. Assistência técnica. Extensão rural. Desenvolvimento rural.

\section{ABSTRACT}

The paper is a reflection about the main services developed by the Institute for Sustainable Development of Agriculture and Forestry of the State of Amazonas (Instituto de Desenvolvimento Agropecuário e Florestal Sustentável do Estado do Amazonas - Idam). It aims to
Márcia Campos Gomes

Mestranda Em Extensão Rural na Universidade Federal de Viçosa, Minas Gerais; integrante do Grupo de Pes-quisa em Conflitos Ambientais, Agricultura e Sociedade (PACAB/UFV) e do Núcleo de Pesquisa e Extensão em Ambiente, Socioeconomia e Agroecologia (NUPEAS/UFAM); bolsista da Fundação de Amparo à Pesquisa do Estado do Amazonas (FAPEAM) (marcinha-taty@ hotmail.com).

Marcelo Leles Romarco de Oliveira

Doutor em Ciências Sociais pela Universidade Federal Rural do Rio de Janeiro, Rio de Janeiro; professor do Departamento de Economia Rural da Universidade Federal de Viçosa, Minas Gerais; coordenador do Grupo de Pesquisa em Conflitos Ambientais, Agricultura e Sociedade (PACAB/UFV) (marceloromarco@gmail.com).

Geusa da Purificação Pereira

Mestranda Em Extensão Rural na Universidade Federal de Viçosa, Minas Gerais; bolsista da Coordenação de Aperfeiçoamento de Pessoal de Nível Superior (CAPES) (geusapereira@ hotmail.com). 
analyze the importance of the Idam for Technical Assistance and Rural Extension (Assistência Técnica e Extensão Rural - Ater) in Amazonas state, identifying how the provision of such services is carried out under the perspective of the National Policy of Technical Assistance and Rural Extension (Política Nacional de Assistência Técnica e Extensão Rural - Pnater). We observe in the theoretical approach that there is a lack of financial incentive and many limitations of the institute, which leads to major problems. The Idam has important role to the development of family farming in the Amazonas state, since they have mediated access to the public policy to these farmers. The Ater services in Brazil and in Amazonas state changed considerably after the implementation of Pnater. Despite the focus of the Ater in the state still be predominantly diffusionist, we observe an efforts of the entity to incorporate the focus of the new Ater. So it is possible to infer that the extensionists from the entity have worked within the limitations as facilitators of the rural development process, helping to improve the lives of farmers of the Amazonas state through the services developed.

Keywords: Familiar farming. Technical assistance. Rural extension. Rural development.

\section{INTRODUÇÃO}

O serviço de extensão rural caracteriza-se como uma atividade importante para o meio rural, exercendo influência no desenvolvimento das atividades dos agricultores assistidos por tais serviços. Desde o seu surgimento, ela tem sofrido algumas alteraçóes no modo de ser desenvolvida sem, contudo, perder a sua relevância para os agricultores e para o espaço rural.

No Brasil, a extensão rural surgiu no final da década de 1940 . Inicialmente, esse serviço foi exercido tendo como base a ideia de que o conhecimento tecnológico, a difusão de novas técnicas agropecuárias e o apoio financeiro, por meio do crédito, contribuiria para o aumento da produção e para a melhoria das condiçôes de vida do meio rural, tendo em vista à modernizaçáo do campo. Nesse momento, a extensão foi pautada meramente no desenvolvimento econômico e na difusão de pacotes tecnológicos e somente os agricultores mais capitalizados 
tinham acesso a esses serviços (FONSECA, 1985).

Nesse sentido, é importante fazer um histórico sintético da extensão rural no Brasil para entendermos como surge a política de Assistência Técnica e Extensão Rural (Ater), que viria priorizar precisamente aqueles agricultores que seriam os menos capitalizados, que são os chamados agricultores familiares ${ }^{1}$.

A extensão rural no Brasil passou por duas fases, a primeira foi o seu surgimento, na década de 1940, com a criação da Associação de Crédito e Assistência Rural de Minas Gerais (Acar-MG), apoiada pelo presidente Juscelino Kubitschek, e a partir de um convênio firmado com a American International Association (AIA). Nesse momento, o intuito era apenas difundir o modelo de extensão norte-americano, que visava meramente modernizar agricultura, inserindo máquinas e insumos agrícolas no campo. A segunda fase com a implementação da Política Nacional de Assistência Técnica e Extensão Rural (Pnater), em janeiro de 2010, a qual preconiza um novo modelo para o desenvolvimento dos serviços de Ater, visando beneficiar, principalmente, os denominados "agricultores familiares". Com o surgimento dessa política, as empresas que prestavam assistência técnica e extensão rural passam a ter a missão de atender, prioritariamente, as necessidades da agricultura familiar, trabalhando de acordo com novos princípios, cujo principal objetivo é contribuir para o desenvolvimento e a melhoria da qualidade de vida dos agricultores, tendo como pressuposto uma extensão pautada em um modelo de base ecológica, respeitando e valorizando os saberes dos envolvidos por meio da aplicação de uma metodologia mais participativa, com um enfoque mais construtivista para cada realidade e visando à eficiência produtiva aliada a melhoria da qualidade de vida das famílias que vivem no meio rural.

Sendo assim, a política de assistência técnica e extensão rural contribui para uma ação institucional e para possibilitar a implantação e a materialização de estratégias de desenvolvimento rural sustentável, capazes de gerar renda e novos meios de trabalho no meio rural (CASTRO, 2005).

Diante dessa realidade, o presente trabalho buscou fazer uma revisão de literatura, trazendo uma reflexão sobre os principais serviços desenvolvidos pelo Instituto de Desenvolvimento Agropecuário
${ }^{1}$ O agricultor familiar, definido pela Lei ${ }^{\circ}$ 11.326, de 24 de julho de 2006, é todo aquele que possui uma área de até quatro módulos fiscais; a máo-de-obra do seu estabelecimento, no que diz respeito às atividades econômicas; deve ser predominantemente da própria família e sua renda familiar, predominantemente oriunda das próprias atividades do seu estabelecimento. 
e Florestal Sustentável do Estado do Amazonas (Idam), que é o principal órgáo responsável pelos serviços públicos de assistência técnica e extensão rural nesse estado, e tem como intuito esclarecer como funciona a prestação dos serviços de Ater praticados pelo Idam junto a agricultores familiares no estado do Amazonas.

\section{Histórico da extensão rural no Brasil}

A primeira experiência de extensão rural no Brasil não é um consenso entre autores que discutem o tema, assim, a sua origem, para alguns, se manifesta no estado de São Paulo e, para outros, no estado de Minas Gerais. Por exemplo, Masselli (1994) afirma que a primeira experiência brasileira de extensão rural foi na década de 1940, no município de Santa Rita do Passa Quatro-SP. Entretanto, outros autores afirmam que foi na Semana do Fazendeiro em Viçosa-MG.

Já a institucionalização da extensão rural no Brasil ocorreu no ano de 1948, a partir do convênio de cooperação técnica e financeira entre a AIA e o governo de Minas Gerais, que deu origem à Associação de Crédito e Assistência Rural de Minas Gerais (Acar-MG). Dessa forma, com a criaçáo da Acar inicia-se o serviço de extensão rural no Brasil (OLIVEIRA, 1999).

De acordo com Fraxe et al. (2008), os serviços de extensão rural tiveram início no país no contexto pós-guerra, com o intuito de promover a melhoria das condiçóes de vida da populaçáo rural e apoiar o processo de modernizaçáo da agricultura, inserindo-se nas estratégias voltadas à política de industrialização do país. Em 1956, no governo de Juscelino Kubitschek, foi criada a Associaçáo Brasileira de Crédito e Assistência Rural (Abcar), constituindo-se, então, um sistema nacional articulado com associaçóes de crédito e assistência rural nos estados. A Abcar tinha como objetivo oferecer crédito rural subsidiado para viabilizar a tarefa de difundir tecnologias para a modernizaçáo dos sistemas produtivos e aumentar a produção agrícola.

Na década de 1960, a modernizaçáo da agricultura brasileira tornou-se mais expressiva em razão da adoção do modelo desenvolvimentista, conhecido como Revolução Verde, que propunha a difusão dos "pacotes tecnológicos" 2 nas propriedades agrícolas. Essa década foi caracterizada por uma orientação do sistema público de extensão rural, se às máquinas do campo, insumos químicos e biológicos, e, ainda, sementes modificadas. 
que tinha como base ideológica a abordagem difusionista, priorizando como público da assistência agricultores com maior potencial para adotar as inovaçôes tecnológicas agrícolas.

Após a metade dos anos de 1970, o Estado criou a Empresa Brasileira de Assistência Técnica e Extensão Rural (Embrater), em substituição à Associação Brasileira de Crédito e Assistência Rural (Abcar). Essa alteração refletia a adoção de um novo modelo para o desenvolvimento rural do país. Nesse período, também foram criadas as empresas de assistência técnica e extensão rural em várias regiōes do país, dentre elas: a Empresa de Assistência Técnica e Extensão Rural do Estado de Minas Gerais (Emater-MG), que substituiu a Acar.

A partir dos meados dos anos de 1980, outras organizaçóes passam a prestar serviços de assistência técnica e extensão rural, dentre elas, estão ONGs, cooperativas e organizaçóes de movimentos sociais. Diante desse cenário, o Governo Federal, por meio da Embrater, organiza a extensão rural do país pelo Sistema Brasileiro de Assistência Técnica e Extensão Rural (Sibrater).

No governo do presidente Fernando Collor de Mello, no ano de 1990, o Estado extingui a Embrater e o Sibrater. Assim, as empresas estaduais de extensão rural passam a depender principalmente dos recursos oriundos dos governos estaduais e municipais. O que leva a restriçóes orçamentarias, sobretudo, no que tange a redução do seu quadro de extensionistas e corte nos recursos financeiros.

Assim, com a falta de apoio do Governo Federal aos serviços de Ater e sem a existência de uma política nacional para o setor, alguns estados, no intuito de reestruturar os serviços, buscaram criar mecanismos de financiamento e operacionalização para empresas oficiais (REZENDE, 2012). Segundo Dias (2008), nesse mesmo período, surgiram e se expandiram várias iniciativas, com o objetivo de suprir a ausência de incentivo do Estado, destacando-se aquelas patrocinadas por prefeituras municipais, ONGs e organizaçôes de agricultores, entre outras.

Não obstante, cabe destacar que tanto a Constituição Federal de 1988 quanto a Lei Agrícola de 1991 determinavam que o Estado mantivesse os serviços de Ater públicos e gratuitos para agricultores que possuíssem pequena propriedade, compromisso este que o 
Ministério do Desenvolvimento Agrário (MDA) resgata a partir da implementação da Pnater, em 2010, estabelecendo atender as necessidades da agricultura familiar, de forma coerente com as estratégias de desenvolvimento do meio rural.

No final de 2003, o Estado, na figura do MDA, por meio do Departamento de Assistência Técnica e Extensão Rural (Dater), ligado à Secretaria da Agricultura Familiar (SAF), cria uma nova Política Nacional de Assistência Técnica e Extensão Rural (Pnater), que foi criada por meio de um amplo processo participativo de discussão e consulta à sociedade, envolvendo vários atores sociais com a finalidade de estabelecer as diretrizes para as novas açóes de Ater no Brasil (CAPORAL; RAMOS, 2006).

Esse processo de discussão de uma nova política de extensão foi marcado por muitos embates e várias orientaçôes ideológicas. Nesse sentido, é importante citar a questão da agroecologia, em que, nos primeiros documentos, a partir de 2003, a mudança produtiva sempre estava associada a questóes agroecológicas, ou seja, propunha-se a agroecologia e as dimensões participativas como principais orientaçóes dessa nova política. Entretanto, ao ser promulgada a lei que institui o Pnater (Lei no $12.188 / 2010)^{3}$, retira-se do seu texto a palavra "agroecologia", substituindo-a pela expressão "agricultura de base ecológica”.

Ressalta-se que essa posição nos leva a interpretar que não foi simplesmente uma mudança de lexical, mas, sim, uma disputa ideológica. De certa forma, todo processo participativo que até então a extensão rural vinha passando foi desconsiderado. Discussôes ideológicas à parte, a reestruturação dessa política possibilitou nortear o novo modelo dos serviços de Ater no país, e priorizou como público beneficiário o agricultor familiar.

\section{Surgimento da Ater no Amazonas e a contextualização dos serviços de Ater do Idam no estado do Amazonas}

No estado do Amazonas, as primeiras ações oficiais de Ater se deram a partir da criação da Associação de Crédito e Assistência Rural do Amazonas (Acar/AM), fundada em dezembro de 1966 com o objetivo de prestar orientaçôes técnicas aos produtores rurais. As primeiras
A Lei no 12.188, de 11 de janeiro de 2010, institui a Política Nacional de Assistência Técnica e Extensão Rural para a Agricultura Familiar e Reforma Agrária (Pnater), cria o Programa Nacional de Assistência Técnica e Extensão Rural na Agricultura Familiar e na Reforma Agrária (Prona-ter), e dá outras providências (BRASIL, 2010). 
ações de campo aconteceram no município do Careiro da Várzea, no entanto, o primeiro escritório instalado pela Acar/AM começou a funcionar no município de Itacoatiara no ano de 1967 (IDAM, 2015).

Os trabalhos desenvolvidos pela equipe pioneira dos serviços de Ater no Amazonas eram voltados para a busca de conhecimentos sobre os hábitos e costumes do povo interiorano, respeitando o saber e a percepção popular, pois, naquela época, o extrativismo era a atividade predominante na região (IDAM, 2015).

A extensão rural pública no Amazonas ao longo dos anos passou por algumas mudanças institucionais. No ano de 1977, o Governo do estado extingue a Acar e cria a Empresa de Assistência Técnica e Extensão Rural do estado do Amazonas (Emater/AM), vinculada à Secretaria de Estado de Produção Rural e Abastecimento (Sepror) e associada à Empresa Brasileira de Assistência Técnica e Extensão Rural (Embrater) (FEITOZA, 2003).

Inicialmente, a Emater/AM implantou 43 escritórios espalhados por todo estado, cujas principais atividades, orientadas pela Ater da época, eram agricultura, pecuária, pesca artesanal, piscicultura, preservação do meio ambiente, organizaçóes associativas e noçóes sobre bem-estar social às famílias dos produtores rurais. Além disso, a instituição tentava prestar assistência técnica aos demais municípios que náo possuíam unidades instaladas (Idam, 2015).

No ano de 1993, a Emater/AM foi transformada em Instituto de Desenvolvimento Rural do Estado do Amazonas. Esse novo órgão assumiu toda a estrutura e os trabalhos executados pela Emater/ AM, no entanto, permaneceu com a mesma sigla (Idam, 2015). Posteriormente, no ano de 1995, os serviços de extensão rural foram transferidos para Companhia de Desenvolvimento do Estado do Amazonas (Ciama).

Em 18 de março de 1996, por meio da Lei Estadual no 2.384, foi então criado o Instituto de Desenvolvimento Agropecuário do Estado do Amazonas (Idam), como uma autarquia de personalidade jurídica de direito público, autonomia administrativa, financeira e técnica com a finalidade de executar as atividades antes desenvolvidas pela Secretaria de Estado de Produção Rural e Abastecimento (Sepror), Coordenadoria de Desenvolvimento dos Agronegócios (Codeagro) e 
a Defesa Agropecuária Estadual. O Idam possui sua sede em ManausAM e sua jurisdição abrange todo território estadual. É uma instituição estadual estruturada com equipes de servidores das áreas técnicas e de apoio administrativo e serviço e atua, exclusivamente, com Ater (FRAXE et al., 2008).

Em maio de 2007, o Idam absorveu parte das atividades da Agência de Florestas e Negócios Sustentáveis do Amazonas (Afloram) e o nome foi alterado para Instituto de Desenvolvimento Agropecuário e Florestal Sustentável do Estado do Amazonas. Porém, a sigla permaneceu a mesma. O órgão é vinculado à Sepror e se faz presente em todos os municípios do estado, totalizando 62 cidades. $\mathrm{O}$ estado do Amazonas se divide em 9 sub-regióes, como mostra o Quadro 1, o Idam atua em todas as sub-regióes com 66 unidades locais. Destacando os municípios de Itacoatiara, Manicoré e Lábrea que possuem dois escritórios cada (IDAM, 2015).

Quadro 1 - Sub-regiões do estado do Amazonas.

\begin{tabular}{ll}
\hline & Sub Regióes \\
\hline 1 & Alto Solimões \\
2 & Jutaí-Solimóes-Juruá \\
3 & Purus \\
4 & Juruá \\
5 & Madeira \\
6 & Alto Rio Negro \\
7 & Rio Negro-Solimões \\
8 & Médio Amazonas \\
9 & Baixo Amazonas \\
\hline
\end{tabular}

Fonte: Plano Operativo do Idam (2013).

O Idam tem como finalidade a supervisão, a coordenação e a execução de atividades de assistência técnica, extensão agropecuária e florestal, no âmbito das políticas e estratégias dos governos federal e estadual para setores agropecuário, florestal, pesqueiro e agroindustrial. Sua missão é:

Contribuir para promoção do desenvolvimento rural sustentável, centrado no fortalecimento das atividades 
agropecuárias, florestais, pesqueiras e agroindustriais, mediante a prestaçâo de serviços de assistência técnica, extensão rural, por meio de processos técnicos e educativos, que assegurem a cidadania e melhoria da qualidade de vida de seus beneficiários. (PLANO OPERATIVO, 2013, p. 7).

De acordo com a missão, é possível inferir que os objetivos do Idam vão ao encontro da missão proposta pela Lei de Ater, que preconiza que as entidades que prestam esse serviço tenham como missão:

Participar na promoção e animação de processos capazes de contribuir para a construção e execução de estratégias de desenvolvimento rural sustentável, centrado na expansão e fortalecimento da agricultura familiar e das suas organizaçóes, por meio de metodologias educativas e participativas, integradas às dinâmicas locais, buscando viabilizar as condiçôes para o exercício da cidadania e a melhoria da qualidade de vida da sociedade. (BRASIL, 2004, p. 9).
${ }^{4}$ Decreto $\mathrm{n}^{\circ}$ 6.040, de fevereiro de 2007, que estabelece a criação da Política Nacional de Desen-volvimento Sustentável dos Povos e Comunidades Tradicionais, define populaçóes e comunida-des tradicionais como: grupos culturalmente diferenciados e que se reconhecem como tais, que possuem formas próprias de organizaçāo social, que ocupam e usam territórios e recursos naturais como condiçấo para sua reproduçáo cultural, social, religiosa, ancestral e econômica, utili-zando conhecimentos, inovaçóes e práticas gerados e transmitidos pela tradiçấo.

No que se refere aos serviços de Ater executado pelo Idam, o Plano Operativo do órgão, no ano de 2013, apresenta que a instituição atendeu cerca de 95 mil beneficiários em 2.010 comunidades, sendo aproximadamente $93 \%$ desse público agricultores familiares, de forma que a maioria encontra-se em comunidades tradicionais ${ }^{4}$, dentre elas, foram atendidas $1.429 \mathrm{em}$ todo estado. Para o atendimento dessa demanda e o cumprimento das atividades realizadas pelo órgão, o recurso humano disponível é formado por 663 servidores/ colaboradores. No Quadro 2 é apresentado o corpo de técnicos do Idam. 
Quadro 2 - Número de servidores e qualificação dos técnicos do Idam.

\begin{tabular}{llllll}
\hline $\begin{array}{l}\text { Servidores } \\
\text { locados no } \\
\text { interior do } \\
\text { Amazonas }\end{array}$ & $\begin{array}{l}\text { Servidores } \\
\text { na sede }\end{array}$ & $\begin{array}{l}\text { Servidores } \\
\text { com } \\
\text { formaçáa } \\
\text { superior }\end{array}$ & $\begin{array}{l}\text { Servidores } \\
\text { com nível } \\
\text { médio }\end{array}$ & $\begin{array}{l}\text { Servidores } \\
\text { com nível } \\
\text { fundamental }\end{array}$ & $\begin{array}{l}\text { Total de } \\
\text { servidores }\end{array}$ \\
\hline 444 & 219 & 194 & 434 & 35 & 663 \\
\hline
\end{tabular}

Fonte: Plano Operativo do Idam (2013).

É importante destacar que alguns desses funcionários são disponibilizados pelas prefeituras das localidades, por meio de parcerias estabelecidas, além de, atualmente, as chamadas públicas do MDA também oferecerem parte do recurso dos projetos para essa finalidade (IDAM, 2013).

Entretanto, apesar do órgão possuir uma equipe multidisciplinar para atender o agricultor familiar do estado, o mesmo relatório afirma que a quantidade de funcionário ainda é incipiente para a execução e o alcance dos objetivos definidos pela entidade, principalmente quando se trata de um estado com uma extensão territorial de $1.570 .746 \mathrm{~km} 2$ e peculiaridades que dificultam o acesso às comunidades rurais do estado, fazendo, assim, com que os desafios de trabalhar com a Ater no Amazonas sejam altamente acentuados quando comparados ao restante do país, devido às dificuldades logísticas da região.

A realidade da Ater no estado parece não divergir muito do restante do país no que se refere à falta de atenção com o setor, levando, assim, a insuficiência desses serviços para atender a demanda da agricultura familiar e das populaçóes que vivem e exercem atividades produtivas no meio rural. Essa realidade é evidenciada como uma problemática geral e as dificuldades de acesso e desafios de trabalhar com Ater na Região Amazônica fazem com que o trabalho da entidade se torne mais custoso e difícil. Nesse sentido, pode-se inferir que o atendimento e todas as atribuiçốes previstas para o órgão impossibilitam uma extensão rural eficaz e contínua como propóe a Pnater.

A prestação de serviço de Ater realizada pelo Idam ocorre mediante a necessidade local e das diferentes políticas públicas que serão trabalhadas junto ao público beneficiário desse serviço. As comunidades rurais atendidas são normalmente as mais próximas das unidades locais. Isso significa que as distantes deixam de ser assistidas 
em função do pouco recurso, seja ele financeiro ou humano. Diante dessa realidade, o que acaba acontecendo é a exclusão dessas pessoas no campo, pois nem todas têm acesso a esses serviços.

Os principais parceiros firmados pela entidade para o alcance de resultados obtidos são o governo estadual e o governo federal, por meio de recursos do Ministério do Desenvolvimento Agrário, Ministério do Meio Ambiente, Ministério da Integração Nacional, Banco da Amazônia e Secretaria de Estado do Meio Ambiente e Desenvolvimento Sustentável.

Em relação às formas de trabalho, a Pnater estabelece que os serviços de Ater devem ser executados mediante a utilização de metodologias participativas, em que se deve privilegiar o potencial da comunidade, interagindo, assim, com o conhecimento dos agricultores familiares e contrapondo-se com a prática extensionista convencional, que estava preocupada simplesmente em transferir pacotes tecnológicos aos agricultores familiares (BRASIL, 2004).

Afirmando a importância de se levar em consideração os conhecimentos das populaçóes enquanto recebedores das ações da Ater, Fraxe (2000) diz ser indispensável a todos aqueles que desempenham atividades junto ao homem do campo conhecer a realidade e os aspectos culturais dos locais que irão trabalhar. Nesse sentido, é importante trazer algumas ponderaçóes sobre a própria Pnater, pois é uma política de caráter nacional que deve ser aplicada em um país com a imensa dimensão territorial e com diversidade sociocultural existente e que acaba, muitas vezes, tornando-se difícil de ser executada, devido às particularidades de cada regiáo do país.

No caso do Idam, um dos principais papéis desempenhados pelos extensionistas é a mediação entre o agricultor e as políticas públicas associadas, principalmente, ao apoio a fomento por meio de crédito rural, produção animal, produção florestal, produção vegetal e de serviços como cadastro ambiental rural, carteira de produtor rural etc.

No tange aos principais serviços executados pelos técnicos, esses são destinados ao acompanhamento na produção vegetal, principalmente os de grãos, fruticultura e hortaliças. Na produção animal, o foco é o fortalecimento das cadeias produtivas relacionadas à bovinocultura, bubalinocultura, avicultura, suinocultura, 
ovinocultura, caprinocultura, aquicultura, pesca e apicultura. Já na produção florestal, madeireira, não madeireira e de animais silvestres. Todos esses serviços visam o fortalecimento dessas cadeias produtivas, com base, principalmente, naquelas identificadas no Programa Amazonas Rural 5 e de maior importância econômica para o estado. Além disso, os técnicos trabalham também com agroindustrialização, com intuito de capacitar a produção e a elaboração de alimentos em pequenas indústrias familiares para melhoria da qualidade dos produtos, a fim de motivar os agricultores a concorrerem de forma competitiva em diferentes mercados (IDAM, 2013).

O acesso ao crédito rural é estimulado pelo Idam, por meio de duas linhas - investimento e custeio - com o intuito de contribuir para o desenvolvimento da produção e da comercialização de produtos agropecuários e florestais. Esse serviço possui aplicabilidade em todas as unidades locais do estado, beneficiando agricultores familiares e demais produtores rurais, além de associações, cooperativas e demais organizações sociais assistidas pelos serviços de Ater dessa instituição (IDAM, 2015).

Visando contribuir para melhor desenvolvimento das atividades do público beneficiário, o Idam trabalha também com serviço de capacitação, destinado tanto aos técnicos e integrantes do quadro administrativos da instituição como também aos agricultores familiares e produtores rurais do estado. Por meio dessas capacitaçóes, o Idam busca ampliar os conhecimentos e contribuir para o melhor desenvolvimento das açôes dos técnicos e os envolvidos nos setores administrativos, para que possam, assim, atender melhor as comunidades assistidas pela instituição. Já com relação aos agricultores, as capacitaçóes visam contribuir para o melhor desenvolvimento de suas atividades, incorporando, por meio dessas capacitaçóes, conhecimentos e habilidades para que executem suas atividades produtivas, utilizando-se de técnicas melhores e mais eficientes, maximizando o aproveitamento dos recursos e minimizando ao máximo as agressóes ao meio ambiente (IDAM, 2015).

Por este mesmo aspecto, são desenvolvidas atividades que visam o fortalecimento de açóes associativas por meio de cursos, dias de campo e palestras. A entidade, também, nos últimos anos, tem trabalhado com a inserção de técnicas agroecológicas, por meio do Projeto de
O Programa Amazonas Rural tem como objetivo tornar o estado autossuficiente em alimentos e produtos agroflorestais, procurando gerar oportunidades de emprego e incentivar o desenvolvimento rural sustentável por meio das culturas tradicionais do Amazonas, tais como: borracha, peixe, frutas regionais e etc. 
Apoio a Agroecologia e a Produção Orgânica do Estado do Amazonas PGPO/AM, que visa estimular os agricultores a produzir de maneira sustentável e sem uso de insumos químicos. No entanto, esse projeto vem sendo prioritariamente executado nas regióes metropolitanas de Manaus.

$\mathrm{Na}$ execução dos serviços desenvolvidos pela instituição no ano de 2013, os principais métodos utilizados podem ser observados no Quadro 3.

Quadro 3 - Métodos usados pelo Idam para realização das atividades de Ater em 2013.

\begin{tabular}{lcc}
\hline \multicolumn{3}{l}{ Atividades e métodos realizados pelo Idam em 2013. } \\
\hline Métodos & Número de atividades & Número participantes \\
\hline Visitas de Ater & 105.075 & - \\
Contato com os agricultores & 131.763 & - \\
nas próprias unidades locais & & \\
Reunióes & 1.921 & 36.405 \\
Demonstraçóes de método & 2.180 & 17.304 \\
Unidades demonstrativas & 225 & 3.251 \\
Unidades de observação & 22 & 201 \\
Excursão & 114 & 2.493 \\
Encontros & 42 & 3.118 \\
Intercâmbios & 8 & 99 \\
Dia de campo & 38 & 1.792 \\
Campanhas & 132 & 22.844 \\
Oficinas & 43 & 820 \\
Seminários & 5 & 692 \\
Palestras & 847 & 17.117 \\
\hline
\end{tabular}

Fonte: Plano Operativo do Idam (2013).

Nesse sentido, apesar da importância dessas açóes, torna-se preponderante apontar o alcance limitado que elas possuem, uma vez que nem todos os agricultores familiares são atendidos e, mesmo para os que são, na maioria das vezes, esse atendimento acontece de forma pontual, o que pode comprometer o desempenho das açóes dos extensionistas e, consequentemente, o alcance de melhores resultados para os agricultores e as comunidades atendidas. Isso é decorrente, 
principalmente, da diversidade de açóes que os extensionistas precisam desenvolver e da falta de recursos humanos e financeiros destinados à instituição para que, assim, as atividades sejam desempenhadas de forma contínua e mais abrangente a fim de contemplar todas as comunidades existentes no estado.

Portanto, a ausência dos recursos necessários à realização da Ater, aliado às especificidades regionais, que dificultam o acesso a determinadas comunidades, tornam-se fatores limitantes para a realização de um serviço de Ater da maneira como preconiza a Pnater, por meio da qual os serviços devem ser realizados de forma contínua.

Sendo assim, para melhor atender as comunidades seria necessário mais investimento na área, considerando as especificidades da região, o que requer maior injeção de recurso para tentar suprir as necessidades desses serviços, uma vez que esses investimentos ampliariam as possibilidades de acesso aos recursos necessários ao custeio das atividades e viabilizaria a contratação de mais profissionais e sua capacitação para desenvolvimento das açóes, possibilitando a intensificação do acompanhamento aos agricultores, conforme essa nova perspectiva de Ater, garantindo, assim, a ampliação dos serviços ao maior número de comunidades a serem atendidas.

Além disso, é importante considerar também que o extensionista, para atuar de acordo com as perspectivas da Pnater, precisa desenvolver açóes nas mais diversas áreas, com intuito de abranger as diferentes políticas e programas criados, principalmente, a partir de 2003, que são importantes para o desenvolvimento das atividades produtivas dos agricultores atendidos. No bojo desses programas, é possível citar o Programa de Aquisição de Alimentos (PAA), Programa Nacional de Alimentação Escolar (Pnae), entre outros, que representam importantes mercados institucionais para a comercialização dos produtos da agricultura familiar, tendo em vista que a ela se caracteriza como um dos maiores entraves para a categoria, o que evidencia ainda mais a necessidade de um olhar atento para o serviço de Ater, em virtude do importante papel que eles possuem para os agricultores familiares e para as regióes, por eles atendidas nas mais diversas áreas.

Essas reflexóes sobre o papel e desafios da Ater no estado do Amazonas nos permite concordar com os argumentos de Fraxe et al. (2008), que aponta que os serviços de extensão rural não estão livres de 
obstáculos, sejam eles associados à falta de estrutura dos órgãos, à falta ou pouca quantidade de técnicos, à variedade de açóes que esses técnicos precisam se envolver ou até mesmo à dificuldade na aplicação de metodologias participativas, que pode ser um importante instrumento que envolva técnicos e agricultores no processo de diálogo e saber desses dois grupos. Essas dificuldades podem estar associadas às próprias raízes históricas da extensão rural que constituem um modo operante, muitas vezes, difícil de ser quebrados. Tais dificuldades podem ser percebidas como característica geral, mas cada regiáo possui suas especificidades.

Diante disso, no texto "La extensión y los serviços de apoyo para la agricultura em América Latina y el Caribe: elementos para la formulación de políticas", o autor González Mejía (2004) faz uma análise dos programas de extensão na região e afirma que a América Latina e o Caribe estáo passando por um processo de mudança no que diz respeito à execução do serviço de extensão rural, deixando de ser meros difusores de tecnologias, com base nos pacotes tecnológicos da revolução verde, e se transformando em instituições com novas iniciativas de desenvolvimento rural sustentável. No entanto, o autor enfatiza que não é uma mudança fácil, pois ainda há muito que se conhecer e avançar neste sentido.

A reflexão que se faz a partir da análise dos serviços de Ater executados pelo Idam no estado do Amazonas é que a adoção de um novo modelo de extensão rural que possibilite a promoção do desenvolvimento rural sustentável, como está prevista na Pnater, requer ainda grandes mudanças e avanços, principalmente no que se refere à necessidade de se trabalhar efetivamente para adoção desses novos princípios que contribuam para o desenvolvimento rural. No entanto, cabe destacar que realizar os serviços de extensão rural não tem sido tarefa fácil não apenas no estado do Amazonas, mas em todo país, pois cada vez mais as instituiçóes de Ater têm ampliado os seus serviços e suas açóes, o que tem levado provavelmente a uma crise de identidade, o que traz, ainda, mais desafios para quem realiza essas açóes.

\section{CONSIDERAÇÕES FINAIS}

Muito embora haja falta de incentivo financeiro e muitas limitações 
da entidade, o que possivelmente desencadeia grandes problemas, não há como negar que o Idam possui um papel preponderante para desenvolvimento da agricultura familiar no estado do Amazonas, agindo como mediador ao acesso às políticas públicas e aos serviços de Ater públicos no estado.

É preciso enfatizar que, com a implementação da Pnater, houve avanços na Ater em todo país e, no estado do Amazonas, não foi diferente. Apesar dos serviços no estado caminharem com dificuldades e obstáculos, o que se percebe é que existe um esforço da entidade de incorporar os eixos que a nova Ater propóe, exemplo disso é a missão e objetivos do órgão, que, ao longo dos anos, foram sofrendo modificaçôes para que suas orientaçóes atendessem o que preconiza a Pnater. Mediante esse fato, é possível inferir que os extensionistas da entidade têm atuado dentro da limitação do órgão como agentes facilitadores do processo de desenvolvimento rural, procurando ajudar a melhorar a qualidade de vida no campo dos agricultores familiares do estado.

Apesar disso, com a implementação dessa política, muita coisa mudou e vem mudando, todavia, é preciso enfatizar que esse é um processo gradual e lento, pois envolve diferentes atores de vários segmentos da sociedade civil e das esferas estaduais, federais, municipais etc.

Portanto, torna-se importante fazer reflexóes sobre a Ater pública do estado para impulsionar e reforçar a importância da entidade na criaçáo de mecanismo que coloquem em prática o que a Pnater propóe, que é uma extensão rural que preconiza um modelo mais humanista, baseado em uma concepção de base ecológica e com mudança no perfil do extensionista, considerando todo potencial do local onde se vai atuar, incluindo o agricultor familiar por meio de metodologias participativas para que eles se tornem agentes do processo e náo meros depósitos de pacote tecnológicos.

\section{AGRADECIMENTOS}

À Fundaçáo de Amparo a Pesquisa do Estado do Amazonas (FAPEAM) pela concessáo de bolsa à Márcia Campos Gomes durante seu período de mestrado. 


\section{REFERÊNCIAS}

BRASIL, Ministério do Desenvolvimento Agrário. Política Nacional de Assistência Técnica e Extensão Rural. Brasília: MDA/SAF/Dater, 2004. p. 6-9.

- Ministério do Desenvolvimento Agrário. Programa

Nacional de Assistência Técnica e Extensão Rural: Brasília: MDA, 2004.

. Lei no 12.188 , de 11 de janeiro de 2010, institui a Política

Nacional de Assistência Técnica e Extensão Rural para a Agricultura Familiar e Reforma Agrária (Pnater), cria o Programa Nacional de Assistência Técnica e Extensão Rural na Agricultura Familiar e na Reforma Agrária (Pronater), e dá outras providências. Disponível em: <http://www.planalto.gov.br/ccivil_03/_Ato2007-2010/2010/ Lei/L12188.htm>. Acesso em: 30 maio 2015.

CAPORAL, F. R; RAMOS, L. F. Da extensão rural convencional à extensáo rural para o desenvolvimento sustentável: enfrentar desafios para romper a inércia. Brasília, DF, 2006.

CASTRO, C. E. F. A pesquisa em agricultura familiar. In: CASTRO, C. E. F. et al. Pontes para o futuro. Campinas: CONSEPA, 2005. p. 7-48.

DIAS, M. M. Políticas públicas de extensão rural e inovaçóes conceituais: limites e potencialidades. Revista Perspectivas em Políticas Públicas, Belo Horizonte. v. 1, n. 1. p. 101-114, jan./jun. 2008.

FEITOZA, M. R. do. Extensão rural no Amazonas: concepçóes pedagógicas no planejamento do IDAM-AM. 2003. $107 \mathrm{f}$. Dissertação (Mestrado Em Extensão Rural) - Universidade Federal de Viçosa, Viçosa, Minas Gerais, 2003.

FRAXE, T. J. P. de. Homens anfíbios: etnografia de um campesinato das águas. São Paulo: Anna Blumer; Fortaleza: Secretaria da Cultura e Desporto do Governo do Estado do Ceará, 2000. 192p.

FRAXE, T. J. P. de et al. Extensáo rural e desenvolvimento sustentável no Amazonas. In: Agroecologia, Extensão Rural e 
Sustentabilidade na Amazônia. Manaus: Fundação Universidade Federal do Amazonas, 2008. p. 24.

HERNÁN, G. M. La extensión y los serviços de apoyo para la agricultura em América Latina y El Caribe: elementos para la formulación de políticas. Disponível em: <http://www.mag.go.cr/ biblioteca_virtual_extension_educ_invest/c20_2_2004.pdf >. Acesso em: 30 de maio de 2015.

IDAM - Instituto de Desenvolvimento Agropecuário e Florestal Sustentável do Estado do Amazonas. Disponível em: <http://www. idam.am.gov.br>. Acesso em: 30 maio de 2015.

. Plano Operativo 2013. Disponível em: <http://www.idam. am.gov.br>. Acesso em: 30 maio de 2015.

MASSELLI, M. C. Extensão rural: novas perspectivas a partir da situação de assentamento. 1994. 200f. Dissertação (Mestrado em Educação) - Faculdade em Educação, Universidade Estadual de Campinas, Campinas, 1994.

OLIVEIRA, M. M. As circunstâncias da criação da extensão rural no Brasil. Caderno de Ciência \& Tecnologia, Brasília, v. 16, n. 2, p. 97-134, maio/ago. 1999.

REZENDE, B. G. Novo perfil de assistência técnica e extensáo rural. 2012. 29f. Trabalho de Conclusão de Curso (Graduação em Agronomia) - Faculdade de Ciências Agrárias, Universidade Federal dos Vales do Jequitinhonha e Mucuri, Diamantina, 2012.

Submetido em 26 de junho de 2015. Aprovado em 31 de julho de 2015. 